\title{
Pyrazolylporphyrin Derivatives as New Potential Ligand for Melanoma Cancer Radiopharmaceutical Kit: In Silico Study
}

\author{
Fransiska Kurniawan*, Rahmana E. Kartasasmita, Daryono H. Tjahjono \\ School of Pharmacy, Bandung Institute of Technology, Jalan Ganesha 10, Bandung 40132, Indonesia
}

Received: 18 September 2014 / Accepted: 30 November 2014

\begin{abstract}
:
Melanoma is the most lethal skin cancer, and it is related to Fibroblast Growth Factor 2 (FGF2) which is important for survival and proliferation of melanocytes. Diagnosis and therapy of melanoma cancer can be performed applying radiopharmaceutical with appropriate ligand. The aim of this research was to obtain new pyrazolylporphyrin derivatives having more potency than $\mathrm{T}_{3,4} \mathrm{BCPP}$ as ligand for melanoma cancer radiopharmaceutical kit. The proposed porphyrin derivatives are several combination of meso-substituent between (methyl-pyrazole)-4-yl and 3,4-bis(carboxymethylenoxy)phenyl and combination of (1,2-dimethyl pyrazolium)-4-yl and 3,4bis(carboxymethylenoxy)phenyl. Nine types of pyrazolylporphyrin derivatives and their labeled-Rhenium (Re) and Technetium (Tc) were studied using molecular docking simulation on both active sites of FGF receptor (PDB ID : 1FQ9) using AutoDock 1.5.6 software. Re$\mathrm{T}_{3,4} \mathrm{BCPP}$ and $\mathrm{Tc}-\mathrm{T}_{3,4} \mathrm{BCPP}$ were used for comparison. From all studied pyrazolylporphyrin derivatives, the 5,10,15-tris-[3,4bis(carboxymethylenoxy) phenyl]-20-(methylpyrazole-4-yl)-porphyrin $\left(\operatorname{Tr}_{3,4} \mathrm{BCPPzP}\right)$ gave the best docking result. For $1^{\text {st }}$ and $2^{\text {nd }}$ active site, $\operatorname{Re}-\operatorname{Tr}_{3,4} \mathrm{BCPPzP}$ has free binding energy values of $-15.10 \mathrm{kcal} / \mathrm{mol}$ and $-17.70 \mathrm{kcal} / \mathrm{mol}$, respectively, while those of $\mathrm{Tc}_{\mathrm{T}} \mathrm{Tr}_{3,4} \mathrm{BCPPzP}$ were $-13.02 \mathrm{kcal} / \mathrm{mol}$ and $-16.23 \mathrm{kcal} / \mathrm{mol}$, respectively. It is shown that the non-cationic porphyrin has better affinity than the cationic one. Considering the results, it was concluded that $\operatorname{Tr}_{3,4} \mathrm{BCPPzP}$ is the most potential ligand for melanoma cancer radiopharmaceutical kit.
\end{abstract}

Key words: $F G F$, ligand, melanoma, molecular docking, pyrazolylporphyrin, radiopharmaceutical kit

\section{Introduction}

Melanoma cancer is the most aggresive and the most lethal skin cancer and arises from melanocytes. Melanocytes are specialized pigmented cells which is dominant in skin. Current therapy for melanoma cancer is by surgery, but it is only effective for an early stages of melanoma cancer. When it is already reach the metastatic stages, it is difficult to treat and does not respond to current therapy. [1]

The receptor which has important roles in melanoma cancer is receptor tyrosine kinase that has function in growth of cancer cell. One important receptor in melanoma cancer is FGFR. Previous study showed that the proliferation and survival of melanocytes depends on FGF2 [2]. Thus, FGFR especially for FGFR2 can be a target of melanoma cancer therapy.

One method that can be used to diagnose and treat melanoma cancer is using radiopharmaceutical. The advantage using radiopharmaceutical is high sensitivity and specificity, rapid, and does not cause pain as surgery [3]. Radiopharmaceutical needs ligand which has high affinity with target as a carrier and the radionuclide that will emit $\gamma$-ray (for diagnostic purpose) and $\beta$-ray (for therapeutic purpose).
Previous study showed that porphyrin can bind selectively with cancer cell but it can not be labelled with radionuclide directly. So, it needs modification to the structure for labelling purpose. It is already known that labelled porphyrin can be used as cancer diagnostic and therapy tools [4]. Considering of these facts, porphyrin derivatives can be a potential ligand for radiopharmaceutical kit.

Water soluble porphyrin such as $5,10,15,20$ - tetrakis [3,4 - bis (carboxymethylenenoxy) phenyl] porphyrin $\left(\mathrm{T}_{3,4} \mathrm{BCPP}\right)$ already proved can be used as radioimaging for melanoma and hepatoma cancer [5]. So, the purpose in this study is to modify the substituent to get a new compound which has smaller size in order to have better solubility in water, better affinity to target, more rapidly localize to target, and has higher target-background ratio [6].

\section{Experimental \\ Macromolecul preparation}

Crystal structure of FGF receptor which was used in molecular docking simulation was downloaded from Protein Data Bank (http://www.rcsb.org/pdb) with PDB ID of 1FQ9. In FGF structure, there are two active sites based on natural ligands bound on 1FQ9. At each macromolecular target, natural ligand and water were removed before being used in simulation.

\footnotetext{
*Corresponding author: Fransiska Kurniawan,

E-mail: fransiska.k@students.itb.ac.id
} 


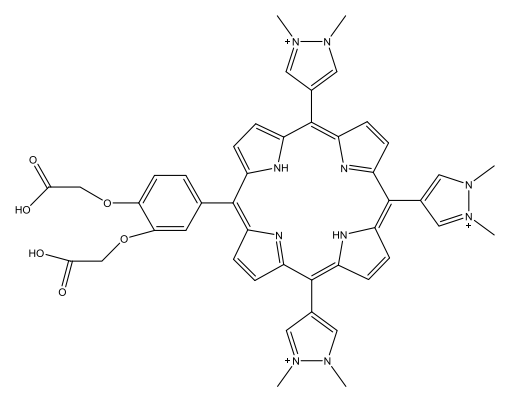

$\mathbf{M}_{3,4} \mathrm{BCPMPzP}$

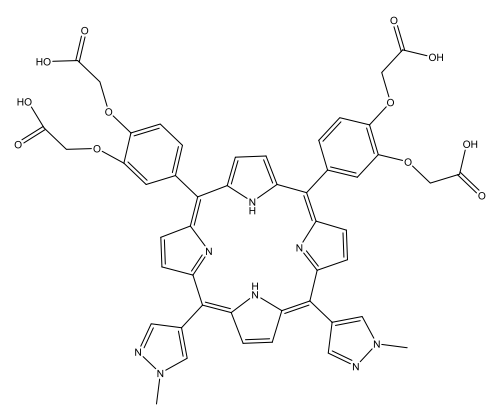

$\mathrm{CD}_{3,4} \mathrm{BCPPzP}$

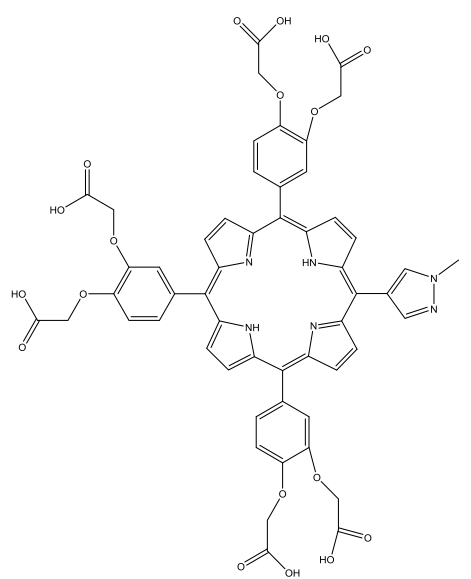

$\operatorname{Tr}_{3,4} \mathrm{BCPPzP}$

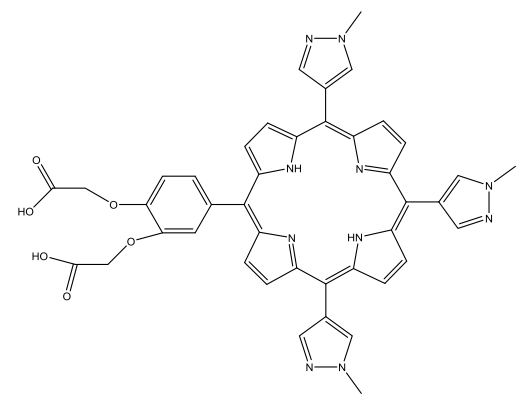

$\mathbf{M}_{3,4}$ BCPPzP

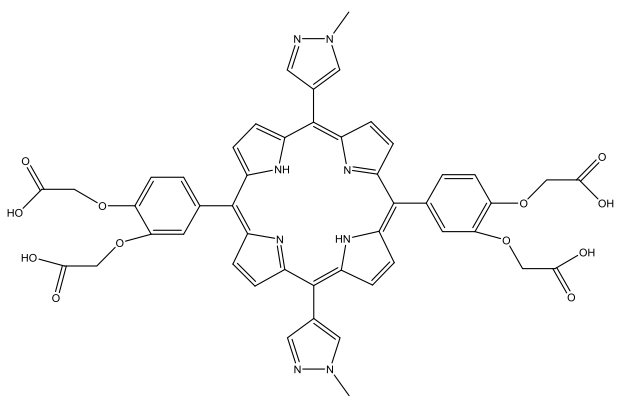

$\mathbf{D}_{3,4} \mathbf{B C P P z P}$

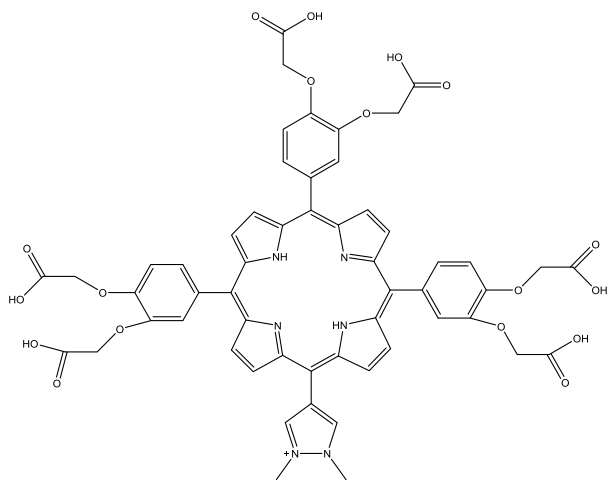

$\operatorname{Tr}_{3,4} \mathbf{B C P M P z P}$

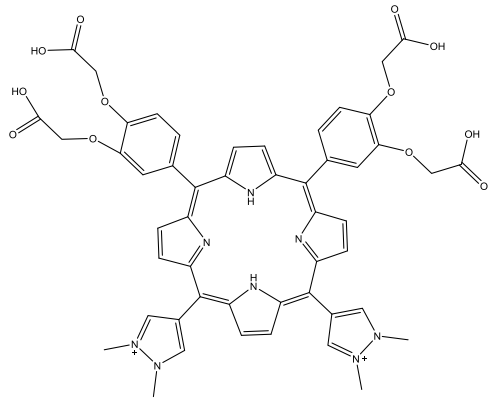

$\mathrm{CD}_{3,4} \mathrm{BCPMPzP}$

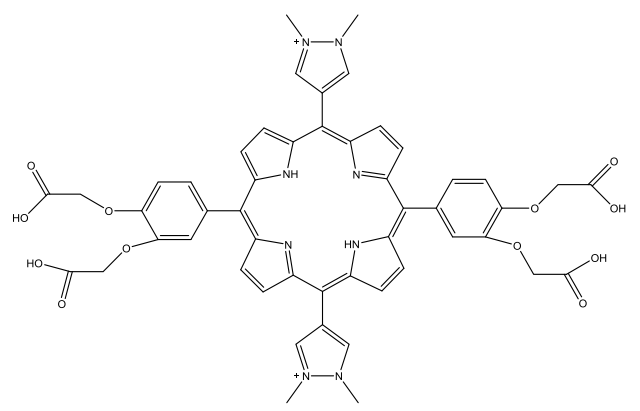

$D_{3,4}$ BCPMPzP

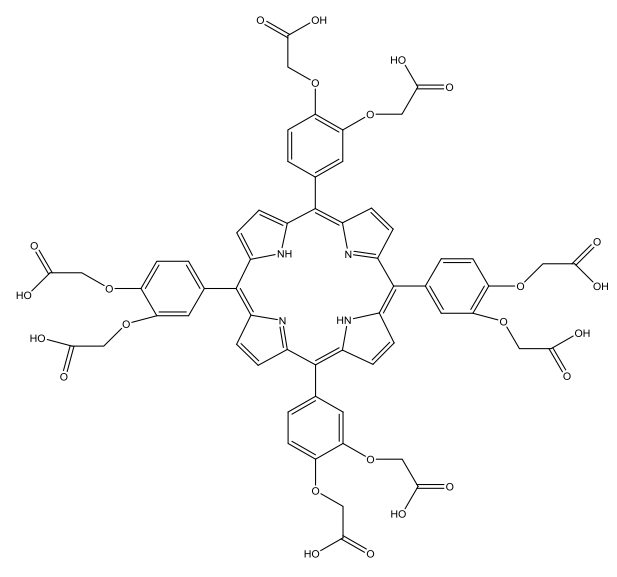

$\mathbf{T}_{3,4} \mathbf{B C P P}$

Figure 1. Eight types of pyrazolylporphyrin derivatives and $\mathrm{T}_{3,4} \mathrm{BCPP}$.

$\mathbf{M}_{3,4} \mathbf{B C P M P z P}=$ 5-mono-[3,4-bis(carboxymethylenoxy) phenyl]-10,15,20-tris-(1,2-dimethylpyrazolium-4-yl)-porphyrin

$\mathbf{M}_{3,4} \mathbf{B C P P z P}=5$-mono-[3,4-bis(carboxymethylenoxy) phenyl]-10,15,20-tris-(methylpyrazole-4-yl)-porphyrin

CD $_{3,4}$ BCPMPzP $=5,10$-di-[3,4-bis(carboxymethylenoxy) phenyl]-15,20-di-(1,2-dimethylpyrazolium-4-yl)-porphyrin

cD $_{3,4}$ BCPPzP $=5,10$-di-[3,4-bis(carboxymethylenoxy) phenyl]-15,20-di-(methylpyrazole-4-yl)-porphyrin

$\mathbf{D}_{3,4} \mathbf{B C P M P z P}=$ 5,15-di-[3,4-bis(carboxymethylenoxy) phenyl]-10,20-di-(1,2-dimethylpyrazolium-4-yl)-porphyrin

$\mathbf{D}_{3,4}$ BCPPzP $=5,15$-di-[3,4-bis(carboxymethylenoxy) phenyl]-10,20-di-(methylpyrazole-4-yl)-porphyrin

$\mathbf{T r}_{3,4} \mathbf{B C P M P z P}=$ 5,10,15-tris-[3,4-bis(carboxymethylenoxy)phenyl]-20-(1,2-dimethylpyrazolium-4-yl)-porphyrin

$\mathbf{T r}_{3,4} \mathbf{B C P P z P}=5,10,15$-tris-[3,4-bis(carboxymethylenoxy)phenyl]-20-(methylpyrazole-4-yl)-porphyrin

$\mathbf{T}_{3,4} \mathbf{B C P P}=5,10,15,20-$ tetrakis $[3,4-$ bis (carboxymethylenenoxy) phenyl $]$ porphyrin 


\section{Ligand preparation}

Figure 1 shows nine types of pyrazolylporphyrin derivatives, which were labelled with $\mathrm{Re}$ and Tc, and were used in the present study. Each ligand structure was built using Gauss View 5.0 and then was optimized using Gaussian 09 on density functional theory method with basis set of 6-31G (for unlabelled porphyrin) and of LANL2DZ (for labelled porphyrin). Structures obtained from geometry optimization were used for molecular docking simulation.

\section{Validation of docking method}

Validation of docking method was performed by redocking procedure, to evaluate the accuracy of docking method. Evaluation was performed by comparing the conformation of natural ligand on 1FQ9 with lowest free binding energy resulted from redocking process and observed X-Ray crystallographic conformation of its. The successful of the docking process is valid if the RMSD $\leqslant 2 \AA[7]$.

\section{Molecular docking}

Molecular docking simulation was performed on both active site of FGF receptor (next called $\mathrm{R} 1$ for $1^{\text {st }}$ active site and $\mathrm{R} 2$ for $2^{\text {nd }}$ active site) using AutoDock 1.5.6.

\section{Results and Discussion}

Geometry optimization was performed to obtain the most stable conformation of the structure, which has the lowest energy $(\Delta H f)$. The result showed (Table 1$)$, that carboxylic derivatives $(3,4-\mathrm{BCP})$ as meso-substituent increase the stability of the structure. Structure with more 3,4-BCP substituent has lower energy. In addition, the labelled porphyrin has lower energy than unlabelled one. Thus, the presence of Re or Tc increase the stability of the structure.

The validation of docking procedure, it showed that the natural ligand of 1FQ9 can interact to the active site method with RMSD $0.77 \AA$ and $0.98 \AA$, respectively. Because the RMSD less than $2 \AA$ (Figure 2), the docking procedure can be applied for docking simulation of porphyrin derivatives to $1 \mathrm{FQ} 9$.

The result of molecular docking simulation is shown in Table 2. It showed that for unlabelled porphyrin, the $\mathrm{cD}_{3,4} \mathrm{BCPPzP}$ has the best affinity to the both active sites on FGFR. After labelling with radionuclide, the affinity of porphyrin derivatives to the receptor changes. For the Re-labelled porphyrins, the best affinity is shown by Re$\mathrm{Tr}_{3,4} \mathrm{BCPPzP}$. In case of Tc-labelled porphyrins, Tc$\mathrm{Tr}_{3,4} \mathrm{BCPMPzP}$ and $\mathrm{Tc}-\mathrm{Tr}_{3,4} \mathrm{BCPPzP}$ gave the best result for $\mathrm{R} 1$ and $\mathrm{R} 2$, respectively. It showed that labeling of porphyrin increase the stability of the structure and also increase the affinity of the porphyrin derivatives to the receptor.

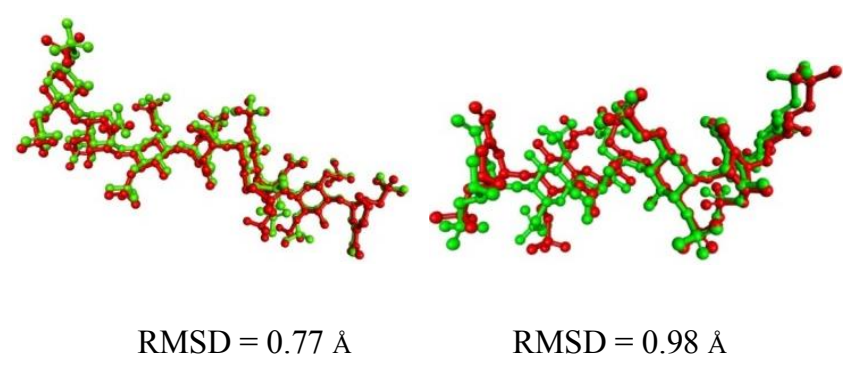

(a)

(b)

Figure 2. Validation of docking procedure of natural ligand (red color) to R1 of 1FQ9 (a) and R2 of 1FQ9 (b). Grid box = $68 \times 58 \times 68$ for R1 and $64 \times 58 \times 40$ for R2. Docking procedure was performed using Genetic Algorithm parameter with 100 runs.

Table 1. Result of Geometry Optimization.

\begin{tabular}{|c|c|}
\hline Compound & $\begin{array}{c}\text { Energy } \\
\left(\Delta \mathrm{H}_{\mathrm{f}}, \text { Hartrees }\right)\end{array}$ \\
\hline $\mathrm{T}_{3,4} \mathrm{BCPP}$ & -4337.06 \\
\hline Tc- ${ }_{3,4} \mathrm{BCPP}$ & -4491.64 \\
\hline $\mathrm{Re}-\mathrm{T}_{3,4} \mathrm{BCPP}$ & -4490.69 \\
\hline $\mathrm{M}_{3,4} \mathrm{BCP} \mathrm{MPzP}$ & -2737.84 \\
\hline Tc-M ${ }_{3,4} \mathrm{BCP} \mathrm{MPzP}$ & -2891.90 \\
\hline Re-M ${ }_{3,4} \mathrm{BCP} \mathrm{MPzP}$ & -2890.95 \\
\hline $\mathrm{M}_{3,4} \mathrm{BCP} \mathrm{PzP}$ & -2618.93 \\
\hline $\mathrm{Tc}-\mathrm{M}_{3,4} \mathrm{BCP}$ PzP & -2773.16 \\
\hline $\mathrm{Re}-\mathrm{M}_{3,4} \mathrm{BCP} \mathrm{PzP}$ & -2772.21 \\
\hline $\mathrm{cD}_{3,4} \mathrm{BCP} \mathrm{MPzP}$ & -3270.96 \\
\hline Tc-cD ${ }_{3,4} \mathrm{BCP} \mathrm{MPzP}$ & -3425.20 \\
\hline Re-cD ${ }_{3,4}$ BCP MPzP & -3424.25 \\
\hline $\mathrm{cD}_{3,4} \mathrm{BCP}$ PzP & -3191.64 \\
\hline Tc-cD ${ }_{3,4}$ BCP PzP & -3345.99 \\
\hline Re-cD ${ }_{3,4} \mathrm{BCP}$ PzP & -3345.04 \\
\hline $\mathrm{D}_{3,4} \mathrm{BCP} \mathrm{MPzP}$ & -3270.97 \\
\hline Tc- $\mathrm{D}_{3,4} \mathrm{BCP} \mathrm{MPzP}$ & -3425.20 \\
\hline $\mathrm{Re}-\mathrm{D}_{3,4} \mathrm{BCP} \mathrm{MPzP}$ & -3424.25 \\
\hline $\mathrm{D}_{3,4} \mathrm{BCP} \mathrm{PzP}$ & -3191.63 \\
\hline Tc- $\mathrm{D}_{3,4} \mathrm{BCP}$ PzP & -3345.99 \\
\hline Re-D ${ }_{3,4}$ BCP PzP & -3345.03 \\
\hline $\mathrm{Tr}_{3,4} \mathrm{BCP} \mathrm{MPzP}$ & -3804.04 \\
\hline $\mathrm{Tc} \mathrm{Tr}_{3,4} \mathrm{BCP} \mathrm{MPzP}$ & -3958.44 \\
\hline $\mathrm{Re}-\mathrm{Tr}_{3,4} \mathrm{BCP} \mathrm{MPzP}$ & -3957.49 \\
\hline $\mathrm{Tr}_{3,4} \mathrm{BCP} \mathrm{PzP}$ & -3764.35 \\
\hline Tc- $\operatorname{Tr}_{3,4} \mathrm{BCP}$ PzP & -3918.82 \\
\hline $\mathrm{Re}-\mathrm{Tr}_{3,4} \mathrm{BCP} \mathrm{PzP}$ & -3917.86 \\
\hline
\end{tabular}


Table 2. Docking result of porphyrin derivatives with 1FQ9

\begin{tabular}{|c|c|c|c|c|}
\hline \multirow[t]{2}{*}{ Compounds } & \multicolumn{2}{|c|}{$\begin{array}{l}\text { Free binding energy } \\
(\mathrm{kcal} / \mathrm{mol})\end{array}$} & \multicolumn{2}{|c|}{ Number of hydrogen bond } \\
\hline & R1 & R2 & R1 & R2 \\
\hline $\mathrm{M}_{3,4} \mathrm{BCPMPzP}$ & -11.64 & -12.77 & 6 & 5 \\
\hline $\mathrm{cD}_{3,4} \mathrm{BCPMPzP}$ & -14.76 & -14.56 & 10 & 11 \\
\hline $\mathrm{D}_{3,4} \mathrm{BCPMPzP}$ & -12.33 & -12.97 & 10 & 9 \\
\hline $\operatorname{Tr}_{3,4} \mathrm{BCPMPzP}$ & -13.35 & -15.24 & 12 & 6 \\
\hline $\mathrm{T}_{3,4} \mathrm{BCPP}$ & -13.62 & -8.05 & 16 & 3 \\
\hline $\mathrm{M}_{3,4} \mathrm{BCP}$ PzP & -12.24 & -14.70 & 6 & 8 \\
\hline $\mathrm{cD}_{3,4} \mathrm{BCP} \mathrm{PzP}$ & -15.17 & -18.16 & 8 & 9 \\
\hline $\mathrm{D}_{3,4} \mathrm{BCP}$ PzP & -11.86 & -16.13 & 8 & 11 \\
\hline $\mathrm{Tr}_{3,4} \mathrm{BCP} \mathrm{PzP}$ & -13.36 & -15.90 & 14 & 8 \\
\hline $\mathrm{Re}-\mathrm{M}_{3,4} \mathrm{BCPMPzP}$ & -7.32 & -9.11 & 1 & 2 \\
\hline Re-cD ${ }_{3,4} B C P M P z P$ & -11.70 & -13.54 & 6 & 8 \\
\hline Re- $\mathrm{D}_{3,4} \mathrm{BCPMPzP}$ & -10.98 & -12.13 & 8 & 4 \\
\hline $\mathrm{Re}-\mathrm{Tr}_{3,4} \mathrm{BCPMPzP}$ & -12.53 & -13.35 & 10 & 8 \\
\hline $\mathrm{Re}-\mathrm{T}_{3,4} \mathrm{BCPP}$ & -13.12 & -12.02 & 14 & 12 \\
\hline Re-M ${ }_{3,4} \mathrm{BCPPzP}$ & -9.92 & -12.24 & 5 & 4 \\
\hline $\mathrm{Re}-\mathrm{cD}_{3,4} \mathrm{BCPP} z \mathrm{P}$ & -11.86 & -16.89 & 5 & 11 \\
\hline Re- $\mathrm{D}_{3,4} \mathrm{BCPPzP}$ & -13.15 & -15.88 & 5 & 8 \\
\hline $\mathrm{Re}-\mathrm{Tr}_{3,4} \mathrm{BCPPzP}$ & -15.10 & -17.70 & 13 & 9 \\
\hline Tc-M ${ }_{3,4} \mathrm{BCPMPzP}$ & -7.74 & -9.08 & 1 & 2 \\
\hline Tc-cD ${ }_{3,4} B C P M P z P$ & -11.97 & -13.52 & 8 & 7 \\
\hline Tc-D ${ }_{3,4}$ BCPMPzP & -10.65 & -12.00 & 7 & 9 \\
\hline Tc- $\mathrm{Tr}_{3,4} \mathrm{BCPMPzP}$ & -13.42 & -14.20 & 8 & 5 \\
\hline $\mathrm{Tc}-\mathrm{T}_{3,4} \mathrm{BCPP}$ & -13.35 & -11.81 & 14 & 5 \\
\hline $\mathrm{Tc}_{\mathrm{C}} \mathrm{M}_{3,4} \mathrm{BCPPzP}$ & -9.82 & -12.19 & 4 & 5 \\
\hline Tc-cD ${ }_{3,4} \mathrm{BCPPzP}$ & -12.25 & -13.46 & 9 & 7 \\
\hline Tc- $\mathrm{D}_{3,4} \mathrm{BCPPzP}$ & -11.62 & -15.67 & 11 & 6 \\
\hline $\mathrm{Tc}-\mathrm{Tr}_{3,4} \mathrm{BCPPzP}$ & -13.02 & -16.23 & 6 & 7 \\
\hline
\end{tabular}

Table 3. Residues of R1 involved in the interaction.

\begin{tabular}{|c|c|c|c|c|c|}
\hline & \multicolumn{5}{|c|}{ Compound } \\
\hline & $\begin{array}{l}\text { Natural } \\
\text { ligand }\end{array}$ & Re- $\operatorname{Tr}_{3,4} \mathrm{BCPPzP}$ & Re- $\operatorname{Tr}_{3,4} \mathrm{BCPMPzP}$ & Tc-Tr ${ }_{3,4}$ BCPPzP & $\mathrm{Tc}^{-\mathrm{Tr}_{3,4} \mathrm{BCPMPzP}}$ \\
\hline Asn27 & $\sqrt{ }$ & $\sqrt{ }$ & & $\sqrt{ }$ & $\sqrt{ }$ \\
\hline Arg120 & $\sqrt{ }$ & & & & \\
\hline Lys125 & $\sqrt{ }$ & $\sqrt{ }$ & $\sqrt{ }$ & $\sqrt{ }$ & $\sqrt{ }$ \\
\hline Lys135 & $\sqrt{ }$ & $\sqrt{ }$ & $\sqrt{ }$ & $\sqrt{ }$ & $\sqrt{ }$ \\
\hline Lys119 & $\sqrt{ }$ & & $\sqrt{ }$ & & \\
\hline Lys 129 & $\sqrt{ }$ & & $\sqrt{ }$ & & \\
\hline Ala136 & $\sqrt{ }$ & $\sqrt{ }$ & $\sqrt{ }$ & & \\
\hline Lys175 & $\sqrt{ }$ & $\sqrt{ }$ & & & \\
\hline Lys177 & $\sqrt{ }$ & $\sqrt{ }$ & & $\sqrt{ }$ & \\
\hline Lys207 & $\sqrt{ }$ & & $\sqrt{ }$ & $\sqrt{ }$ & $\sqrt{ }$ \\
\hline Etc. & - & Gln134, Lys160 & Gln134 & Gly133 & Arg209 \\
\hline
\end{tabular}


Table 4. Residues of R2 involved in the interaction.

\begin{tabular}{|c|c|c|c|c|c|}
\hline & \multicolumn{5}{|c|}{ compound } \\
\hline & $\begin{array}{l}\text { Natural } \\
\text { ligand }\end{array}$ & $\mathrm{Re}-\mathrm{Tr}_{3,4} \mathrm{BCPPzP}$ & Re- $\operatorname{Tr}_{3,4} \mathrm{BCPMPzP}$ & $\mathrm{Tc}-\mathrm{Tr}_{3,4} \mathrm{BCPPzP}$ & $\mathrm{Tc}-\mathrm{Tr}_{3,4} \mathrm{BCPMPzP}$ \\
\hline Lys119 & $\sqrt{ }$ & & & & \\
\hline $\operatorname{Arg} 120$ & $\sqrt{ }$ & & & & \\
\hline Thr121 & $\sqrt{ }$ & & & & \\
\hline Lys125 & $\sqrt{ }$ & $\sqrt{ }$ & & & \\
\hline $\mathrm{G} \ln 134$ & $\sqrt{ }$ & & & & \\
\hline Lys135 & $\sqrt{ }$ & $\sqrt{ }$ & $\sqrt{ }$ & $\sqrt{ }$ & $\sqrt{ }$ \\
\hline Ala136 & $\sqrt{ }$ & & & & \\
\hline Lys207 & $\sqrt{ }$ & & & & \\
\hline Arg209 & $\sqrt{ }$ & $\sqrt{ }$ & & & \\
\hline Lys163 & $\sqrt{ }$ & & $\sqrt{ }$ & & \\
\hline Lys172 & $\sqrt{ }$ & $\sqrt{ }$ & $\sqrt{ }$ & $\sqrt{ }$ & $\sqrt{ }$ \\
\hline Lys175 & $\sqrt{ }$ & $\sqrt{ }$ & & $\sqrt{ }$ & $\sqrt{ }$ \\
\hline Lys177 & $\sqrt{ }$ & & $\sqrt{ }$ & $\sqrt{ }$ & $\sqrt{ }$ \\
\hline Etc. & - & - & Lys26, Tyr103 & Thr173, Asp218 & - \\
\hline
\end{tabular}

The docking result also showed that non-cationic porphyrin derivatives gave better affinity compare to that of the cationic porphyrin. It is predicted due to the labelled non-cationic porphyrin, especially for Re and $\mathrm{Tc} \mathrm{Tr}_{3,4} \mathrm{BCPPzP}$, have more amino acid residue involved in the interaction than the labelled $\operatorname{Tr}_{3,4} \mathrm{BCPMPzP}$. The comparison of residues involved in the interaction between natural ligand and porphyrin derivatives are summarized in Table 3 (for R1) and Table 4 (for R2).

Re- $\operatorname{Tr}_{3,4} \mathrm{BCPP} z \mathrm{P}$ showed the highest affinity from all Relabelled porphyrin. From the above data, it showed that on R1, Re- $\operatorname{Tr}_{3,4} \mathrm{BCPPzP}$ and $\mathrm{Re}-\mathrm{Tr}_{3,4} \mathrm{BCPMPzP}$ has 6 residues involved in the interaction. It is the same member as observed for the natural ligand on R1. However, Re- $\operatorname{Tr}_{3,4} \mathrm{BCPPzP}$ has 2 more amino acid residues (Gln134 and Lys160) and 3 more hydrogen bondings compare to that of $\mathrm{Re}-\mathrm{Tr}_{3,4} \mathrm{BCPMPzP}$. On R2, $\operatorname{Re}-\operatorname{Tr}_{3,4} \mathrm{BCPPzP}$ has 5 same amino acid residues with the natural ligand, whereas the $\mathrm{Re}-\mathrm{Tr}_{3,4} \mathrm{BCPMPzP}$ only has 4 amino acid residues. Moreover, $\mathrm{Re}-\mathrm{Tr}_{3,4} \mathrm{BCPPzP}$ has 3 more hydrogen bondings compare to the Re$\mathrm{Tr}_{3,4} \mathrm{BCPMPzP}$. This may cause result in Re$\mathrm{Tr}_{3,4} \mathrm{BCPPzP}$ has better affinity (has lower free binding energy) than the $\mathrm{Re}-\mathrm{Tr}_{3,4} \mathrm{BCPMPzP}$ on both active sites of 1FQ9.

Tc- $\mathrm{Tr}_{3,4} \mathrm{BCPPzP}$ showed the highest affinity on $\mathrm{R} 2$ from all Re-labelled porphyrin. From the above data, it showed that on R2, each of $\mathrm{Tc}^{-} \mathrm{Tr}_{3,4} \mathrm{BCPPzP}$ and $\mathrm{Tc}-$ $\operatorname{Tr}_{3,4} \mathrm{BCPMPzP}$ has 4 amino acid residues which is the same with the natural ligand on R2 (Lys135, Lys172, Lys175, and Lys177). However, Tc-Tr $3{ }_{3,4} \mathrm{BCPPzP}$ has 2 more amino acid residues (Thr173 and Asp218) and 2 more hydrogen bondings compare to the Tc$\mathrm{Tr}_{3,4}$ BCPMPzP. Upon interaction with R1, Tc$\mathrm{Tr}_{3,4} \mathrm{BCPMPz}$ showed high binding affinity, as also observed for $\operatorname{Tr}_{3,4} \mathrm{BCPPzP}$ to $\mathrm{R} 2$, as well as its Relabelled complexes.

As summarized in Table 2, it also showed that porphyrin derivatives has better affinity to $\mathrm{R} 2$ than to $\mathrm{R} 1$. Tc$\mathrm{Tr}_{3,4} \mathrm{BCPP} z \mathrm{P}$ has free binding energy to $\mathrm{R} 1$ and $\mathrm{R} 2$ -13.02 and $-16.23 \mathrm{kcal} / \mathrm{mol}$, respectively. While Re$\mathrm{Tr}_{3,4} \mathrm{BCPPzP}$ has the free binding energy to $\mathrm{R} 1$ and $\mathrm{R} 2$ -15.10 and $-17.70 \mathrm{kcal} / \mathrm{mol}$, respectively.

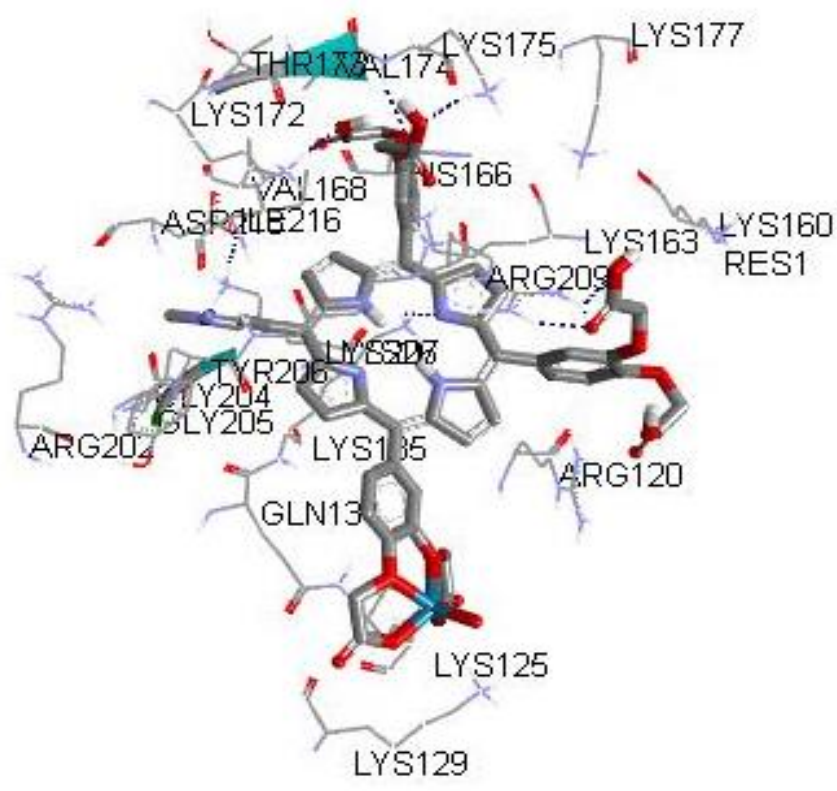

Figure 3. Interaction $\mathrm{Re}-\mathrm{Tr}_{3,4} \mathrm{BCPPzP}$ with $\mathrm{R} 2$ of $1 \mathrm{FQ} 9$. 


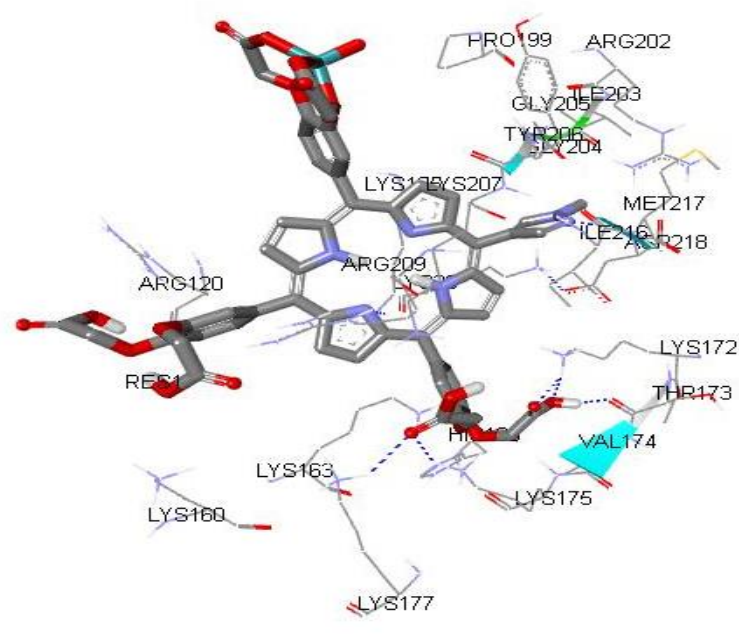

Figure 4. Interaction $\mathrm{Tc}^{-} \mathrm{Tr}_{3,4} \mathrm{BCPPzP}$ with $\mathrm{R} 2$ of $1 \mathrm{FQ} 9$.

\section{Conclusions}

Pyrazolylporphyrin substituted with carboxylic acid derivatives $(3,4-\mathrm{BCP})$ has potency to be a ligand for radiopharmaceutical and labelled $\operatorname{Tr}_{3,4} \mathrm{BCPPzP}$ shows high affinity to R2 of FGF receptor. From all studied pyrazolylporphyrin derivatives, non-cationic porphyrin has better affinity to FGFR than the cationic one. The result of geometry optimization showed that labelling porphyrin derivatives with Re or Tc increase the stability of the structure.

\section{Acknowledgement}

FK thanks Directorate General of Higher Education for PMDSU scholarship.

\section{References}

[1] V.G. Schopfer, C. Wellbrock, and R. Marais, Nature, 445, 2007, 851-857.

[2] M.G. Gartside, H. Chen, O.A. Ibrahimi, S.A. Byron, A.V. Curtis, C.L. Wellens, A. Bengston, L.M. Yudt, A.V. Eliseenkova, J. Ma, J.A. Curtin, P. Hyder, U.L. Harper, E. Riedesel, G.J. Mann, J.M. Trent, B.C. Bastian, P.S. Meltzer, M. Mohammadi, and P.M. Pollock, Mol Cancer Res, 7(1), 2009, 41-54.

[3] A. Owunmane, Patel and M. Sadek, The Handbook of Radiopharceuticals, $1^{\text {st }}$ Ed, Chapman and Hall Medical, London, 1995, 59.

[4] Murugesan S., S.J. Shetty, T.S. Srivastava, O.P.D. Noronha, and A.M. Samuel, Journal of Porphyrins and Phthalocyanines, 5, 2001, 824-828.

[5] Z. Jia, H. Deng, and S. Luo, European Journal of Nuclear Medicine and Molecular Imaging, 35, 2008, 734-742.

[6] Y. Lee, The Open Nuclear Medicine Journal, 2, 2010, 178185.

[7] F.N. Novikov and G.G. Chilov, Mendeleev Communications, 19, 2009, 237-242. 